\title{
Nicotinic Stimulation Produces Multiple Forms of Increased Glutamatergic Synaptic Transmission
}

\author{
Kristofer A. Radcliffe and John A. Dani \\ Division of Neuroscience, Baylor College of Medicine, Houston, Texas 77030-3498
}

Synaptic modulation and long-term synaptic changes are thought to be the cellular correlates for learning and memory (Madison et al., 1991; Aiba et al., 1994; Goda and Stevens, 1996). The hippocampus is a center for learning and memory that receives abundant cholinergic innervation and has a high density of nicotinic acetylcholine receptors (nAChRs) (Wada et al., 1989; Woolf, 1991). We report that strong, brief stimulation of $\mathrm{nAChRs}$ enhanced hippocampal glutamatergic synaptic transmission on two independent time scales and altered the relationship between consecutively evoked synaptic currents. The nicotinic synaptic enhancement required extracellular calcium and was produced by the activation of presynaptic $\alpha 7-$ containing $\mathrm{nAChRs}$. Although one form of glutamatergic enhancement lasted only for seconds, another form lasted for minutes after the nicotinic stimulation had ceased and the nicotinic agonist had been washed away. The synaptic enhancement lasting minutes suggests that nAChR activity can initiate calcium-dependent mechanisms that are known to induce glutamatergic synaptic plasticity. The results with evoked synaptic currents showed that $\mathrm{nAChR}$ activity can alter the relationship between the incoming presynaptic activity and outgoing postsynaptic signaling along glutamatergic fibers. Thus, the same information arriving along the same glutamatergic afferents will be processed differently when properly timed nicotinic activity converges onto the glutamatergic presynaptic terminals. Influencing information processing at glutamatergic synapses may be one way in which nicotinic cholinergic activity influences cognitive processes. Disruption of these nicotinic cholinergic mechanisms may contribute to the deficits associated with the degeneration of cholinergic functions during Alzheimer's disease.

Key words: glutamate synaptic transmission; nicotinic acetylcholine receptors; hippocampal cultures; synaptic modulation; learning; memory
Certain forms of the synaptic changes that are thought to underlie learning and memory (Madison et al., 1991; Aiba et al., 1994; Goda and Stevens, 1996; McHugh et al., 1996) can be influenced by cholinergic interaction with glutamatergic transmission (Ohno et al., 1993; Maurice et al., 1994; Aigner, 1995). In vivo studies have shown that cholinergic neurons contribute to arousal, attention, learning, and memory (Levin, 1992), but the synaptic events underlying those functions are poorly understood. It is known that the hippocampus receives cholinergic innervation mainly from the medial septum-diagonal band complex (Kasa, 1986; Woolf, 1991; Alonso and Amaral, 1995; Yoshida and Oka, 1995). Choline acetyltransferase and acetylcholinesterase share a similar wide distribution in the hippocampus, supporting the conclusion that there are dense cholinergic fibers in the infrapyramidal layer. Ligand binding studies and in situ hybridization for nicotinic acetylcholine receptor (nAChR) subuinit-specific mRNA indicate that there is strong expression of the $\alpha 7$ and $\beta 2$ subunits throughout the rat hippocampus, with weaker expression of other subunits (Deneris et al., 1988; Wada et al., 1989; Cimino et al., 1992; Dineley-Miller and Patrick, 1992; Séguéla et al., 1993).

Neuronal nAChRs are composed of five subunits that are arranged around a central cation-selection ion channel (Cooper et al., 1991; Unwin, 1995). Although many subtypes of nAChRs can be constructed from different subunit combinations, two main

\footnotetext{
Received April 1, 1998; revised June 11, 1998; accepted June 24, 1998.

This work was supported by grants from the National Institute of Neurological Disorders and Stroke (NS21229) and the National Institute of Drug Abuse (DA09411). K.R. was supported in part by the William Stamps Farish Fund.

Correspondence should be addressed to Dr. John A. Dani, Division of Neuroscience, Baylor College of Medicine, Houston, TX 77030-3498.

Copyright (C) 1998 Society for Neuroscience $0270-6474 / 98 / 187075-09 \$ 05.00 / 0$
}

neuronal categories can be identified on the basis of their function and pharmacology. In heterologous expression systems most neuronal nAChRs are constructed from combinations of $\alpha$ - and $\beta$-subunits (Conroy et al., 1992; Sargent, 1993; McGehee and Role, 1995; Ramirez-Latorre et al., 1996; Role and Berg, 1996; Wonnacott, 1997). Only $\alpha 7, \alpha 8$, and $\alpha 9$ can form homooligomeric receptors that are inhibited by $\alpha$-bungarotoxin $(\alpha$ BGT), and only $\alpha 7$ is widely expressed in the mammalian brain (Couturier et al., 1990; Schoepfer et al., 1990; Bertrand et al., 1993; Séguéla et al., 1993). The function and complete composition of native $\alpha$-BGT-sensitive nAChRs found in neurons are still under study. These native $\alpha$-BGT receptors share properties with $\alpha 7$ homo-oligomeric channels expressed in oocytes, leading to the conclusion that $\alpha 7$ is among the subunits that comprise native mammalian $\alpha$-BGT-sensitive neuronal nAChRs (Alkondon and Albuquerque, 1993; Amar et al., 1993; Anand et al., 1993; Séguéla et al., 1993; Castro and Albuquerque, 1995; Flood et al., 1997).

Recently, it was found in both hippocampal slices and tissue culture that low concentrations of nicotine applied for minutes can increase the frequency of miniature EPSCs (mEPSCs; Gray et al., 1996) (also see Vidal and Changeux, 1993; McGehee et al., 1995; Lena and Changeux, 1997). That synaptic enhancement was short-lived, however, peaking and then declining while nicotine was present. Furthermore, that weak nicotinic stimulation did not induce the concerted activation of nAChRs that might be expected during cholinergic synaptic activity. In this study we used brief, strong agonist applications to activate nAChRs synchronously and found that nicotinic stimulation can initiate multiple forms of enhanced glutamatergic transmission in cultured rat hippocampal neurons. 


\section{MATERIALS AND METHODS}

Tissue culture. Hippocampal cell cultures were prepared as described previously (Zarei and Dani, 1994, 1995; Gray et al., 1996). Sprague Dawley rats $(<3$ d old) were anesthetized with halothane and were decapitated. Hippocampi were dissected in ice-cold balanced salt solution [BSS; containing (in $\mathrm{mM}$ ) $1.8 \mathrm{CaCl}_{2}, 0.81 \mathrm{MgSO}_{4}, 5.4 \mathrm{KCl}, 140$ $\mathrm{NaCl}, 5.55$ D-glucose, and 5 HEPES with 0.01-0.1 gm/1 phenol red, $\mathrm{pH}$ 7.3] and were incubated in a sterile enzyme solution (BSS supplemented with $1.5 \mathrm{~mm} \mathrm{CaCl} \mathrm{Cl}_{2}, 0.5 \mathrm{~mm}$ EDTA, $0.2 \mathrm{mg} / \mathrm{ml} \mathrm{L}$-cysteine, and $20 \mathrm{U} / \mathrm{ml}$ papain) at $37^{\circ} \mathrm{C}$ in $5 \% \mathrm{CO}_{2}$ for $30 \mathrm{~min}$ with gentle rocking. The tissue was washed and dissociated by trituration in MEM supplemented with $10 \%$ fetal bovine serum (FBS; HyClone Laboratories, Logan, UT), $10 \%$ horse serum (HS; Life Technologies, Gaithersburg, MD), 20 mM glucose, $1 \mu \mathrm{l} / \mathrm{ml}$ serum extender (Mito +; Collaborative Biomedical Products), 50 $\mathrm{U} / \mathrm{ml}$ penicillin/streptomycin (Life Technologies), $2.5 \mathrm{mg} / \mathrm{ml}$ trypsin inhibitor, and $2.5 \mathrm{mg} / \mathrm{ml} \mathrm{BSA}$. Cells were plated at 70,000-450,000 cells $/ \mathrm{ml}$ onto microislands (Bekkers and Stevens, 1991) that were prepared by coating coverslips with a thin layer of $0.15 \%$ agarose. Then the slips were sprayed with a mixture of $0.05 \mathrm{mg} / \mathrm{ml}$ poly-D-lysine and $0.25 \mathrm{mg} / \mathrm{ml}$ collagen, using a glass microatomizer. Cells were kept at $37^{\circ} \mathrm{C}$ in $5 \% \mathrm{CO}_{2}$ and fed 2-3 times per week with MEM supplemented with 5\% HS, 20 $\mathrm{mM}$ glucose, $50 \mathrm{U} / \mathrm{ml}$ penicillin/streptomycin, $1 \mu \mathrm{l} / \mathrm{ml}$ serum extender, 10 $\mathrm{mM} \mathrm{MgCl}_{2}, 0-0.5 \mu \mathrm{M}$ tetrodotoxin (TTX), 0-1 nM methyllycaconitine (MLA), and $0-0.5 \%$ w/v BSA and were studied between days 15 and 25 . TTX and MLA were used often in the culture media to decrease synaptic activity that might have produced excitotoxicity or may have overly potentiated the synapses before our electrophysiology studies. Glial proliferation was inhibited on days $3-5$ by $5 \mu \mathrm{M}$ cytosine arabinof uroside. Animal care was in accordance with institutional guidelines.

Electrophysiology and solutions. Electrophysiology and solution exchange techniques were as we have described previously (Gray et al., 1996). Patch pipettes for patch-clamp recordings were prepared from glass capillary tubing (Garner Glass, Claremont, CA), and currents were amplified and filtered at $1-2 \mathrm{kHz}$. Very rapid agonist applications were achieved by using a linear array of flow pipes $(375 \mu \mathrm{m}$ inner diameter; Garner Glass) controlled by computer via valves (General Valve, Fairfield, NJ) in the solution pathway. The distance between the flow pipe opening and the cell was typically $100-150 \mu \mathrm{m}$, which produced rapid solution exchange (peak currents in $<10 \mathrm{msec}$ ) and slower washout when the valves closed again (complete in $\sim 200 \mathrm{msec}$ ). The five rapid nicotinic agonist applications that were used to increase the frequency of mEPSCs were delivered at $8.5 \mathrm{sec}$ intervals to allow the nAChRs to recover partially from desensitization. These agonist applications and all solution changes influenced all of the nAChRs on the surface of the voltageclamped neuron and on the presynaptic terminals from other neurons that formed synapses on the clamped neuron. For the studies of mEPSCs there were usually one to five neurons on the tissue culture microisland. Thus, any one or more of those neurons could have had vesicular glutamate release enhanced by the nicotine application. This experimental condition led to a higher probability of seeing nicotinic enhancement of mEPSC frequency. Electrical artifacts arising from valves were blanked from the traces for display purposes.

An Axobasic program from the laboratory of Dr. Charles F. Zorumski (Washington University, St. Louis, MO) was adapted for the off-line analysis of mEPSCs. To follow the minutes-scale enhancement of mEPSC frequency, we continually monitored synaptic activity for many minutes before and following $\approx 2 \mathrm{sec}$ after the last of five rapid nicotine applications. These mEPSCs were collected before nicotine arrived (as the control) and after the nicotine had been washed off completely. Thus, the minutes-scale changes in mEPSC frequency continued well after the nicotine was removed. In this case the mEPSCs were collected into $15 \mathrm{sec}$ bins for frequency plots and into $3 \mathrm{pA}$ bins for amplitude plots. The short-lasting seconds-scale enhancement of mEPSC frequency did not last long enough to follow with continuous recordings. This burst of mEPSCs immediately followed a nicotine application. The acquisition of this seconds-scale enhancement of mEPSCs occurred during the protocol of the five nicotine applications. Therefore, this increased frequency of mEPSCs was not grouped with and was on a very different time scale from the continuous recordings of synaptic events collected before and after the nicotine applications. Baseline noise was monitored throughout the analysis at least every $102.4 \mathrm{msec}$. Data were discarded from analysis for any one of several reasons: changes in leak after nicotine application, changes in baseline noise when comparing before with after nicotine application, poor signal-to-noise ratio for mEPSC analysis, and instability of the baseline frequency of mEPSCs. CNQX (10 $\mu \mathrm{M}$; 6-cyano-7- nitroquinoxaline-2,3-dione) with $1 \mathrm{~mm} \mathrm{MgCl}_{2}$ completely blocked the mEPSCs, indicating glutamatergic transmission. In some cases the mEPSC traces were filtered digitally off-line for clarity.

Solutions for the patch-clamp experiments were as follows: external (in $\mathrm{mm}), 150 \mathrm{NaCl}, 0-5 \mathrm{CaCl}_{2}, 0-2 \mathrm{MgCl}_{2}, 2.5 \mathrm{KCl}, 10$ glucose, $10 \mathrm{HEPES}$ $0-0.2 \mathrm{CdCl}_{2}$, and $0-0.1$ picrotoxin plus $1 \mu \mathrm{M}$ TTX, $1 \mu \mathrm{M}$ atropine sulfate, and 0-1 $\mu \mathrm{M}$ strychnine, $\mathrm{pH} 7.3,310-325 \mathrm{mOsm}$; internal solution in the patch pipette (in $\mathrm{mM}$ ), $140 \mathrm{CsMeSO}_{3}, 5 \mathrm{NaCl}, 2 \mathrm{Na}_{2} \mathrm{ATP}, 2$ MgATP, 0-0.3 Na $\mathrm{NaTP}_{3}$ 0.2 EGTA, and $10 \mathrm{HEPES}, \mathrm{pH} 7.3,300-310$ mOsm. Picrotoxin was usually, but not always, present to inhibit GABAergic synaptic transmission to produce more quiet baselines for the mEPSCs. In some experiments the NMDA subtype of glutamate receptors was inhibited by $50-250 \mu \mathrm{M}$ AP-5, and $1 \mathrm{mM} \mathrm{MgCl}_{2}$ was usually present. For the pharmacological characterization of the rapid nicotinic currents, $10 \mu \mathrm{M}$ CNQX was included to inhibit excitatory synaptic transmission to allow for better visualization of the nicotinic currents. Internal solutions often were supplemented with an ATP-regenerating system ( $20 \mathrm{~mm}$ phosphocreatine and $60 \mathrm{U} / \mathrm{ml}$ creatine phosphokinase) to decrease the rundown of nicotinic currents (Lester and Dani, 1994). Perforated patches (Rae et al., 1991) were used for all four experiments in Figure $2 B$ (Gray et al., 1996).

\section{RESULTS}

\section{Seconds-scale enhancement of mEPSCs}

Figure $1 A$ shows a paradigm for enhanced vesicular release of glutamate that occurred on the time scale of seconds (seconds scale; Alkondon et al., 1996). After the application of $0.5 \mathrm{~mm}$ nicotine (or 1-3 mM acetylcholine) to activate nAChR currents, there was an immediate increase in the frequency of mEPSCs ( $n=19$ of 27 neurons). The mEPSCs were shown to be glutamatergic because they were inhibited completely by glutamate receptor antagonists, $10 \mu \mathrm{M}$ CNQX plus $100 \mu \mathrm{M}$ AP-5 and/or 1 $\mathrm{mm} \mathrm{MgCl}_{2}$ (data not shown). During these experiments the voltage-gated sodium and calcium channels were inhibited by 1 $\mu \mathrm{M}$ TTX and $200 \mu \mathrm{M} \mathrm{CdCl}{ }_{2}$, respectively. The burst of mEPSCs decayed back to the baseline frequency before the next nicotine application ( $8.5 \mathrm{sec}$ later). The recovery can be noted by the quiet baseline before each of the five applications of nicotine in Figure $1 \mathrm{~A}$.

The solution changes used to apply nicotine were extremely rapid, requiring computer-controlled valves. Therefore, we tested whether the solution changes could be causing some unexpected artifact, for instance, by deforming the membrane. To the same neuron that was used in Figure $1 A$, we applied bath solution (control) by the same method used to apply nicotine (Fig. 1B). This control did not increase the mEPSC frequency, but nicotine applications before and after the control did produce bursts of mEPSCs, indicating that the nicotinic currents underlie the seconds-scale frequency increase.

Nicotine was applied to this neuron in six separate series, with up to 20 nicotine applications per series. On a time scale of seconds, each nicotine application increased mEPSC frequency above the baseline by an average of $830 \% \pm 90 \%$ ( \pm SEM). Despite the burst of mEPSCs immediately after each nicotine application, there was no change in frequency seen on a longer time scale. In Figure $1 C$ the six separate series of nicotine applications are aligned at the downward arrow. The time that it took for the nicotine applications is not shown. The normalized number of mEPSCs was collected into $15 \mathrm{sec}$ bins, beginning $\approx 2 \mathrm{sec}$ after the last nicotine application in each series. On that longer time scale, no increase in mEPSC frequency was observed because the brief increase in mEPSC frequency had returned to baseline in much less than one bin.

Although the frequency of the mEPSCs was increased by nicotinic currents, the amplitudes were not. Figure $1 D$ shows that 
A

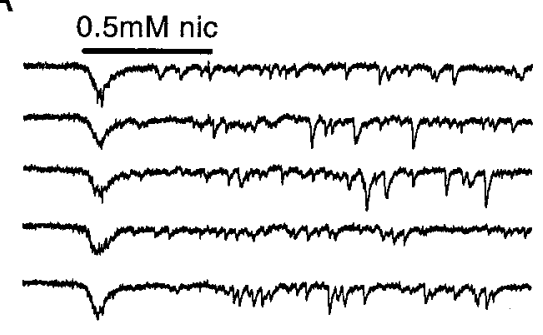

C

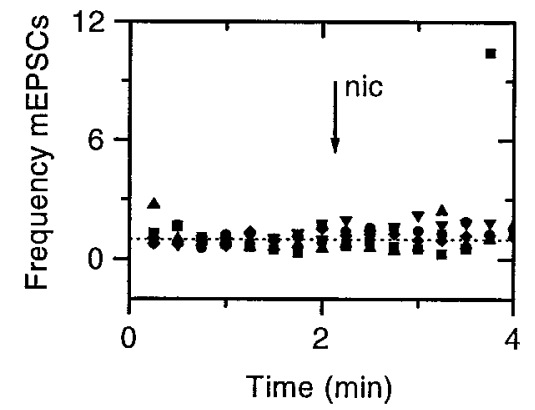

B

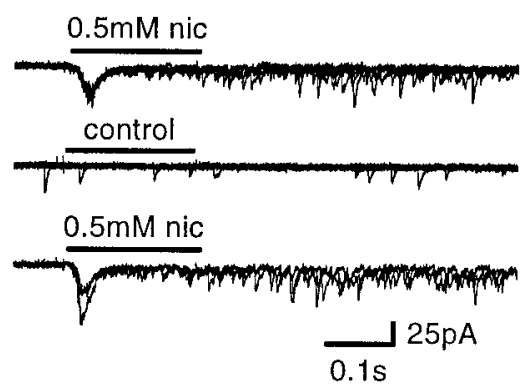

D

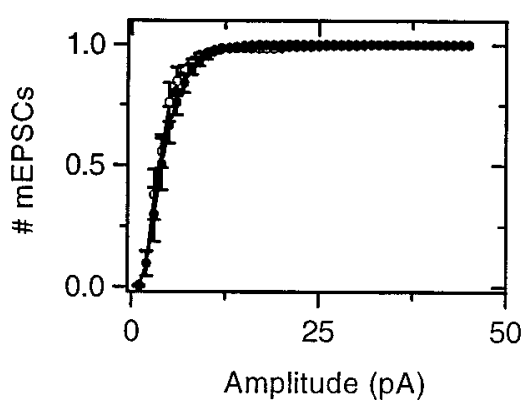

Figure 1. Nicotine-induced currents increase the frequency of mEPSCs on the seconds time scale. A, Applications of 0.5 $\mathrm{mM}$ nicotine (solid bar) activate $\mathrm{nAChR}$ currents that are followed by an abrupt increase in glutamatergic mEPSC frequency. Before the next nicotine application $(8.5 \mathrm{sec})$ the mEPSC frequency declined to the baseline value, as can be seen by the quiet baseline before each nicotine application. $B$, To test for artifacts, we applied nicotine-free solutions (control) using the same solution/application methods. Five applications of the control solution (five traces are overlaid) did not increase the frequency of mEPSCs, but nicotine applied before (top five traces overlaid) and after (bottom three traces overlaid) the control did increase the frequency. $C$, In six separate attempts that are aligned (arrow, nic), 3-20 applications of nicotine did not increase the frequency of mEPSCs for this same neuron on the minutes time scale (15 sec/bin beginning $2 \mathrm{sec}$ after the last nicotine application). The time taken for the nicotine applications is not shown. During the nicotine applications the mEPSC frequency increased on average $830 \%$, but this seconds-scale increase did not last long enough to be observed by the recordings beginning $2 \mathrm{sec}$ after the last nicotine application. The mEPSC frequency before the nicotine applications is normalized to one for plotting purposes. $D$, The amplitudes of the mEPSCs do not change after activating nAChR currents. Cumulative amplitude distributions were created from the mEPSCs before (open circles) each nicotine application and for the $400 \mathrm{msec}$ after the nicotinic current ( filled circles). The two distributions overlap.

the amplitudes of the mEPSCs were the same before the nicotine applications as they were during the peak of the increased frequency.

Most of the neurons (64\%) displayed nicotinic currents. The vast majority of the responding neurons had currents with rapid activation and desensitization kinetics (163 of 167 neurons), which are indicative of $\alpha$-BGT-sensitive nAChRs that contain the $\alpha 7$ subunit (Couturier et al., 1990; Alkondon and Albuquerque, 1991, 1993; Alkondon et al., 1992; Zorumski et al., 1992; Séguéla et al., 1993; Zhang et al., 1994; Gray et al., 1996). Those nicotinic currents were inhibited completely by $50 \mathrm{~nm} \alpha$-BGT $(n=9)$ or another $\alpha 7$-specific inhibitor, $5 \mathrm{~nm}$ MLA $(n=14)$. In all cases, when the nicotinic currents were inhibited, the seconds-scale enhancement of mEPSCs was prevented (Fig. 2A). Although the inhibition of nicotinic currents by $\alpha$-BGT was irreversible during $>1 \mathrm{hr}$ of wash $(n=3)$, inhibition by MLA was reversed by washing for $5 \min (n=4$; Fig. $2 B)$.

Previous research has shown that $\alpha 7$-containing nAChRs have a relatively high $\mathrm{Ca}^{2+}$ permeability (Vijayaraghavan et al., 1992; Séguéla et al., 1993; Pugh and Berg, 1994; Castro and Albuquerque, 1995); therefore, we tested whether external $\mathrm{Ca}^{2+}$ was required for the nicotinic enhancement of glutamate release. In $\mathrm{Ca}^{2+}$-free solutions the nicotine applications did not increase the frequency of mEPSCs on the seconds time scale $(n=9)$. Furthermore, when nicotinic stimulation produced an increase in mEPSC frequency, if we then removed the external $\mathrm{Ca}^{2+}$, nicotinic currents could no longer increase the frequency of mEPSCs on the seconds scale ( $n=4$; Fig. $2 C$ ). When compared with the currents in 2 or $5 \mathrm{~mm}$ calcium, it was typical that the peaks of the nicotinic currents were smaller and the kinetics slower in calciumfree solutions. This modulation of nicotinic currents by external $\mathrm{Ca}^{2+}$ changes has been described previously (Mulle et al., 1992; Vernino et al., 1992; Amador and Dani, 1995; Bonfante-Cabarcas et al., 1996). This $\mathrm{Ca}^{2+}$ modulation was not the basis for preventing nicotine-induced enhancement of mEPSC frequency, because even with large nicotinic currents the mEPSC frequency did not increase in calcium-free external solutions. In Figure $2 D$ the frequency of mEPSCs is normalized to the rate before the nicotinic currents were activated separately in both 0 and $5 \mathrm{~mm}$ calcium $(n=4)$. Only when applied in the calcium-containing solution did nicotine increase the frequency of mEPSCs.

\section{Minutes-scale enhancement of mEPSCs}

Synchronous activation of $\mathrm{nAChR}$ currents also could increase the frequency of mEPSCs on the time scale of minutes (minutes scale, Fig. $3 A$ ). Again these were glutamatergic mEPSCs that could be inhibited completely by $10 \mu \mathrm{M}$ CNQX and $100 \mu \mathrm{M}$ AP-5 and/or $1 \mathrm{mM} \mathrm{Mg}^{2+}$. After monitoring the baseline frequency of mEPSCs for several minutes, we rapidly applied $0.5 \mathrm{~mm}$ nicotine (or 1-3 mm acetylcholine) for five consecutive times to activate nAChRs (Fig. $3 A$, middle current traces). The nicotine was applied for $200 \mathrm{msec}$ and immediately washed away each time to allow 8.5 sec for recovery from desensitization before the next application. After the fifth and last nicotine application the nicotine was washed away, and in $2 \mathrm{sec}$ the recordings of mEPSCs began again. During these experiments the voltage-gated sodium and calcium channels were inhibited by $1 \mu \mathrm{M}$ TTX and $200 \mu \mathrm{M} \mathrm{CdCl}_{2}$, respectively. The frequency of the mEPSCs (Fig. 3B), but not the amplitudes (Fig. $3 C$ ), increased on the minutes time scale $(n=10$ of 27 neurons). The standard protocol for activating nicotinic currents was five applications of agonist. When that stimulation failed to increase the frequency of mEPSCs, more applications of nicotine sometimes could elicit an increase $(n=2$ of 7 trials; Fig. 4). This result suggests that stronger stimulation is more likely to achieve some threshold that is not reached by fewer applications of agonist. 

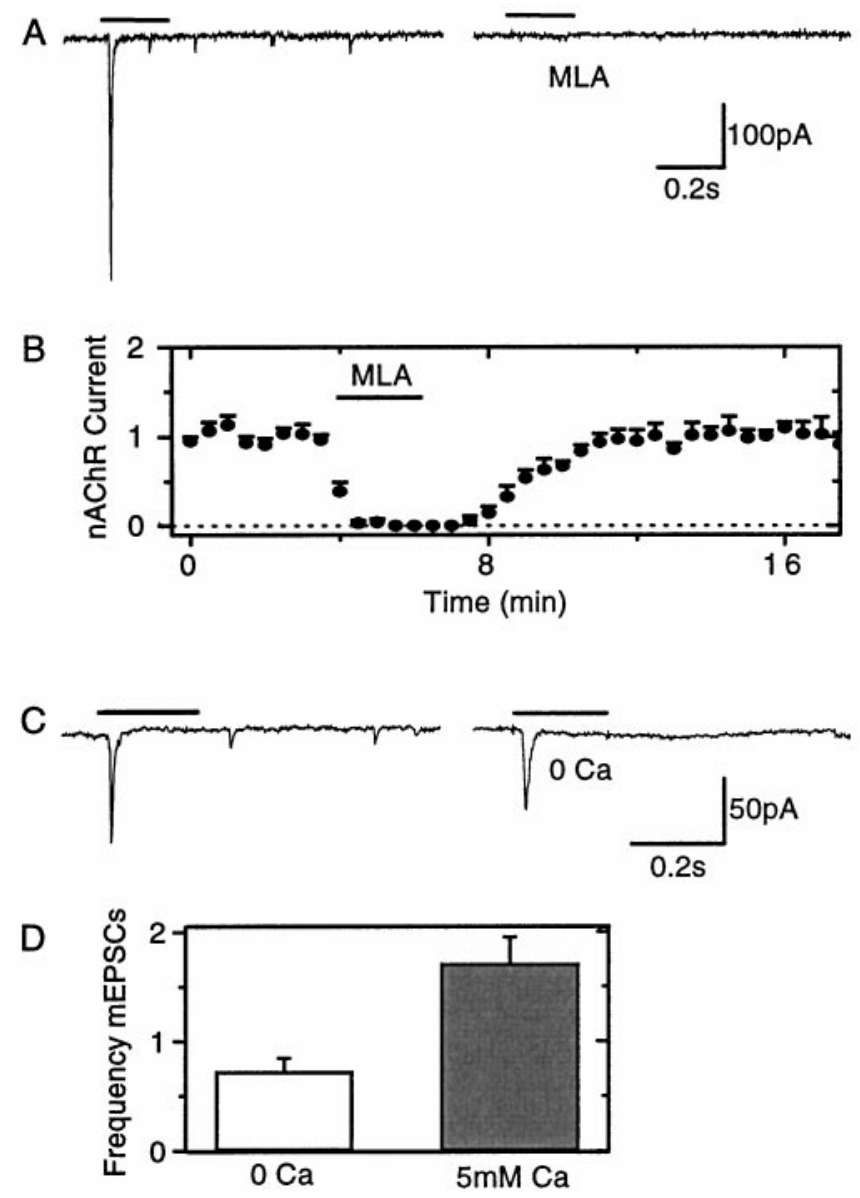

Figure 2. The nicotine-induced seconds-scale increase in mEPSC frequency has the pharmacology of $\alpha 7$-containing $\mathrm{nAChRs}$ and requires external calcium. $A$, A specific inhibitor of $\alpha 7$-containing nAChRs, $5 \mathrm{~nm}$ MLA, completely blocked the nicotine-induced currents $(0.5 \mathrm{~mm}$ nic, solid bars) and prevented the mEPSCs that followed the nicotinic currents. $B$, Nicotinic currents were inhibited completely by $0.5 \mathrm{~nm}$ MLA (solid bar), but those currents recovered after being washed. The time course for inhibition and recovery of the nicotinic currents is shown $(n=$ 4 neurons, \pm SEM). The peak nAChR currents before MLA treatment were normalized to one to average currents from different neurons. $C$, In a solution containing $5 \mathrm{mM} \mathrm{Ca}^{2+}$, the frequency of mEPSCs increased after nicotinic currents were activated $(0.5 \mathrm{mM}$, solid bar $)$. In the same cell when the $\mathrm{Ca}^{2+}$ was absent $\left(0 \mathrm{mM} \mathrm{Ca}^{2+}\right)$, nicotine applications (solid bar) did not increase mEPSC frequency. $D$, In $\mathrm{Ca}^{2+}$-free and $5 \mathrm{~mm} \mathrm{Ca}^{2+}$ solutions, the frequency of mEPSCs was measured in the same neurons $(n=4)$ immediately after nicotine-induced currents. The frequency of mEPSCs before nicotine was applied was normalized to one to combine results from different neurons. The frequency of mEPSCs increased only after nicotinic currents that were activated in the $\mathrm{Ca}^{2+}$-containing solution.

Because the nAChR currents could be inhibited by MLA and then could recover during a 5 min wash, we used MLA to test whether $\alpha 7$-containing receptors mediated the minutes-scale increase in mEPSC frequency. MLA inhibited the nicotinic currents and the minutes-scale enhancement of mEPSC frequency ( $n=7$; Fig. $5 A$ ), but after MLA was washed away, nicotinic stimulation could increase the frequency of mEPSCs $(n=1$ of 3 ; Fig. 5B).

The minutes-scale increase in mEPSC frequency required external calcium. When $\mathrm{Ca}^{2+}$ was removed from the external solution, nicotine stimulation no longer increased the frequency of mEPSCs $(n=9$; Fig. $5 C)$. However, after $1-2.5 \mathrm{mM} \mathrm{Ca}^{2+}$ was added back to the external solution in seven of the nine experiments, the frequency could be increased ( $n=2$ of 7; Fig. $5 D$ ).

Initially, we incorrectly thought that the seconds-scale increase in mEPSC frequency (see Fig. 1) was required to obtain the longer minutes-scale form of glutamatergic enhancement (see Fig. 3). We reasoned that inducing the minutes-scale effect required a higher threshold of stimulation than was needed for the seconds-scale enhancement. Although that simple threshold hypothesis may hold in some cases, it does not always apply. We found that 19 of 27 neurons showed a seconds-scale increase in mEPSC frequency and 10 of 27 showed the minutes-scale increase, but only 7 of 27 neurons showed both forms. Stated in an alternative manner, 12 of 27 neurons had a seconds-scale increase without the minutes-scale form, and 3 of 27 had a minutes-scale increase without the seconds-scale form. Thus, the two forms of increased mEPSC frequency are not necessarily linked, and it seems they can occur independently of each other.

\section{Nicotinic currents affect evoked EPSCs}

Nicotinic modulation also was observed during evoked glutamatergic synaptic transmission (eEPSC) at autaptic synapses or at synapses between two coupled hippocampal neurons (see Mennerick and Zorumski, 1995, 1996). Pairs of voltage stimulations separated by $100 \mathrm{msec}$ were applied to the presynaptic neuron (Fig. 6A). Individual pairs of eEPSCs were separated by $16 \mathrm{sec}$. During that $16 \mathrm{sec}$ the $\mathrm{nAChR}$ currents could be activated by nicotine applications (Fig. 6A, arrowheads). The first currents of each eEPSC pair that are displayed in Figure $6 A$ are plotted as open circles in Figure $6 B$. The solid bar indicates the period of time when nicotinic currents were being activated. The electrical stimulations during the nicotine-induced currents evoked larger glutamatergic eEPSCs. Figure $6 B$ also shows the usual trend that the eEPSCs became steadily smaller as the experiment progressed, as noted by the slight downward slope of the eEPSC amplitudes. In the three cases in which it was tested, a second set of nicotine applications coming at later times caused a smaller or no increase in the eEPSC amplitude (Fig. 6B, second bar). On average, the amplitude of the first eEPSC of the pair increased by $46 \% \pm 24 \%$ ( $n=10$ trials in 8 of 26 neurons).

In addition to the increased amplitude of the first eEPSC, nicotine pulses also altered the relationship between the two eEPSCs of the pair (Fig. 6C,D). While obtaining the baseline eEPSCs, we occasionally saw paired-pulse facilitation (eEPSC2 > eEPSC1) (3 of 10). Usually, however, there was paired-pulse depression (eEPSC2 < eEPSC1) (Wu and Saggau, 1994; Mennerick and Zorumski, 1995, 1996; Stevens and Wang, 1995). In all cases in which nicotine increased the amplitude of the evoked currents, eEPSC1 increased more than eEPSC2 (Fig. 6D). The paired-pulse ratio (PPR) of the amplitudes (eEPSC2/eEPSC1) always decreased.

\section{DISCUSSION}

Nicotinic stimulation initiated multiple forms of enhanced glutamatergic synaptic transmission. In each case the effect of nicotine was dependent on the presence of extracellular $\mathrm{Ca}^{2+}$ and occurred via the activation of presynaptic $\alpha 7$-containing nAChRs. Two apparently independent forms of modulation increase the frequency of spontaneous miniature EPSCs. One form is on the time scale of seconds, whereas the other is on the time scale of minutes. Synchronous stimulation of $\mathrm{nAChRs}$ also can increase 
A

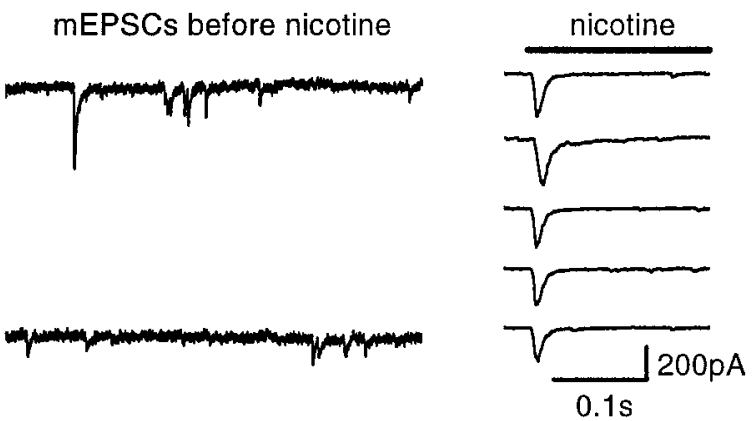

B

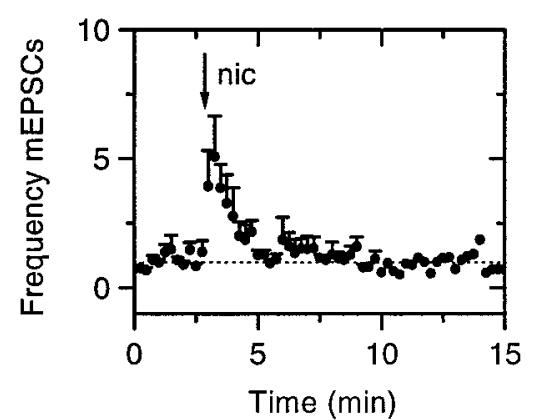

C

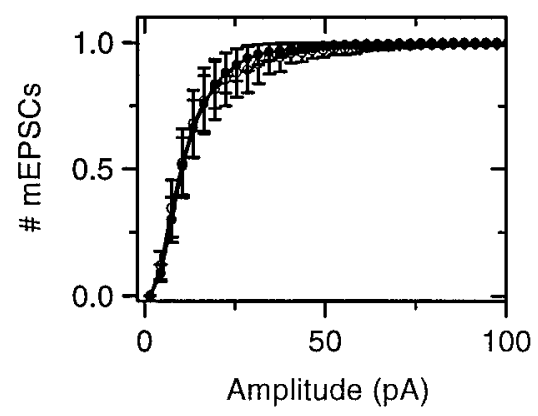

Figure 3. Nicotine-induced currents increase the frequency of mEPSCs on the minutes time scale. $A$, Glutamatergic mEPSCs are shown before and after five applications of $0.5 \mathrm{~mm}$ nicotine. The nicotine-induced nAChR currents (middle five records) rapidly activated and desensitized. After each $200 \mathrm{msec}$ nicotine application the nicotine was washed away rapidly to allow $8.5 \mathrm{sec}$ for recovery from desensitization before the next application. Nicotine was not present when the mEPSC recordings recommenced $2 \mathrm{sec}$ after the last nicotine application. $B$, The mEPSC frequency increased after activating the nAChR currents (arrow). After $\approx 4$ min, the frequency returned to the baseline. The mEPSC frequency before nicotine was normalized to a baseline of one (dotted line) so that experiments with different baseline frequencies could be averaged. The arrow indicates the five applications of $0.5 \mathrm{~mm}$ nicotine (13 trials from 10 neurons, \pm SEM). The nicotine applications took $\approx 35$ $\mathrm{sec}$, but that time gap is not shown. The continuous recording of mEPSCs was restarted within a couple of seconds after the last nicotine application. $C$, The amplitudes of the mEPSCs did not change after activating nAChR currents. Cumulative amplitude distribu-

tions were created from the mEPSCs before (open circles) and after (closed circles) the five nicotine applications. The two distributions overlap.

the amplitude of evoked EPSCs. The enhanced evoked release of glutamate continues for several minutes. On a much shorter time scale of $100 \mathrm{msec}$, nicotinic currents decrease the ratio of evoked pairs of EPSCs (PPR). The first evoked EPSC of a pair was increased more than the second eEPSC.

\section{Role of presynaptic nAChRs}

Previously published results and aspects of the present data indicate that presynaptic nAChRs are important. Nicotinic AChRs located at presynaptic terminals or at preterminal locations have been shown to enhance the release of various neurotransmitters in tissue culture, brain slices, and synaptosomes (for review, see McGehee and Role, 1995; Role and Berg, 1996; Wonnacott, 1997). Particularly at GABAergic synapses, the activation of preterminal nAChRs is thought to depolarize the membrane locally, leading to the activation of voltage-dependent channels that directly mediate the $\mathrm{Ca}^{2+}$ influx underlying enhanced GABA release (Lena et al., 1993; McMahon et al., 1994; Alkondon et al., 1997; Lena and Changeux, 1997). The agonist-induced effect mediated by preterminal nAChRs was inhibited by TTX, which blocks $\mathrm{Na}$ channels and thereby prevents the regenerative voltage activation of $\mathrm{Ca}^{2+}$ channels in the terminal. GABAergic terminals also can have nAChRs. In hippocampal cultures, evidence supports the conclusion that presynaptic nAChRs can affect GABA release much as they affect glutamate release (Radcliffe et al., 1998).

At glutamatergic synapses, low concentrations of nicotine were found to increase the frequency of mEPSCs and to elevate presynaptic $\mathrm{Ca}^{2+}$ via a TTX-insensitive mechanism (McGehee et al., 1995; Gray et al., 1996). In those cases, presynaptic $\alpha 7$ containing nAChRs were capable of directly mediating a $\mathrm{Ca}^{2+}$ influx that initiated the enhanced glutamate release. It seems extremely likely that $\mathrm{nAChRs}$ located on terminals and preter- minals have varying degrees of importance in regulating the release of many neurotransmitters in different areas of the brain (Vidal and Changeux, 1993; Alkondon et al., 1996; Albuquerque et al., 1997; Lena and Changeux; 1997; Wonnacott, 1997; Guo et al., 1998; Li et al., 1998).

In this study, presynaptic $\alpha 7$-containing nAChRs are capable of mediating the effects we observed. In all of our experiments in which we measured mEPSCs, action potentials were blocked by TTX, and in most cases $\mathrm{Cd}^{2+}$ also was used to inhibit voltagegated $\mathrm{Ca}^{2+}$ channels. The decrease in the PPR and the increase in the frequency, but not the amplitude, of the mEPSCs both suggest that the final expression of nicotinic stimulation resides presynaptically. That is not to say, however, that nAChRs located away from presynaptic terminals or located postsynaptically are not important (see Wang and Kelly, 1997; Wonnacott, 1997). The hypothesis that the present forms of nicotinic modulation reside presynaptically is consistent with results from hippocampal slices showing that low concentrations of nicotine directly increase the presynaptic concentration of $\mathrm{Ca}^{2+}$ (Gray et al., 1996) (also see Alkondon et al., 1996; Role and Berg, 1996; Wonnacott, 1997). The nicotine-induced $\mathrm{Ca}^{2+}$ influx was monitored with fura-2 from single mossy fiber presynaptic terminals while inhibiting glutamate, $\mathrm{Na}^{+}$, and $\mathrm{Ca}^{2+}$ channels (Gray et al., 1996). The density and distribution of nAChRs, particularly the highly $\mathrm{Ca}^{2+}$ permeable $\alpha 7$-containing receptors, will influence the strength and type of synaptic modification initiated by cholinergic activity (see Moss and Role, 1993; Rathouz and Berg, 1994; Rathouz et al., 1995; Wilson Horch and Sargent, 1996; Ullian et al., 1997). Evidence is accumulating that these mechanisms are active at many different types of synapses, including GABA, 5-HT, ACh, dopamine, and norepinephrine, as well as the glutamatergic synapses that were examined here (for review, see McGehee and 


\section{a before nicotine}
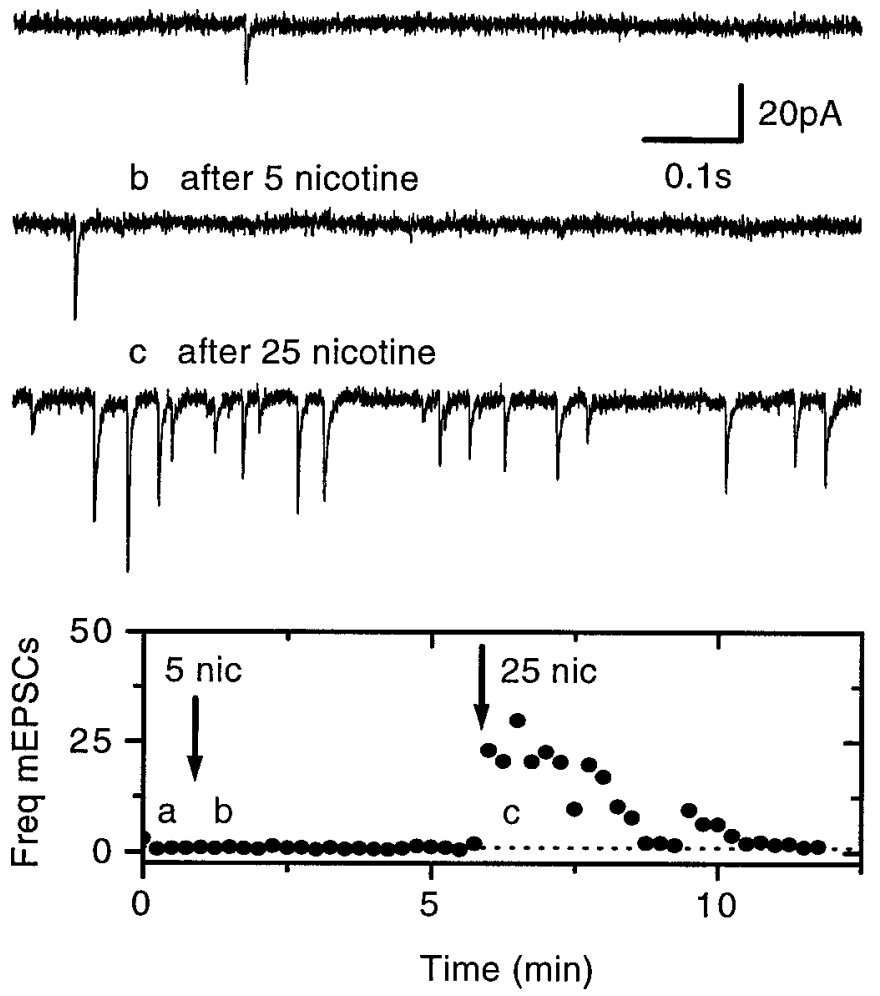

Figure 4. A larger number of nicotine applications is more likely to increase the frequency of mEPSCs. Five applications of $0.5 \mathrm{~mm}$ nicotine (arrow, 5 nic) activated $\mathrm{nAChR}$ currents but did not increase the frequency of mEPSCs. However, 25 applications of nicotine (arrow, 25 nic) did increase the frequency. Representative recordings of mEPSCs are shown before nicotine $(a)$, after five applications of nicotine $(b)$, and after 25 applications of nicotine $(c)$. The time course of the frequency of mEPSCs during the experiment is shown below, with letters indicating when the traces shown above the time course were collected. The time taken for the nicotine applications (arrows) is not shown.

Role, 1995; Role and Berg, 1996; Albuquerque et al., 1997; Wonnacott, 1997).

\section{Multiple time scales for nicotinic enhancement of mEPSC frequency}

It is reasonable to hypothesize that the presynaptic action of calcium entering via $\alpha 7$-containing $\mathrm{nAChRs}$ contributes to the observed increase in mEPSC frequency. On the seconds time scale or when the changes in PPR are considered, nAChRs might provide a sufficient local $\mathrm{Ca}^{2+}$ signal to increase directly the probability of vesicular release or to increase the availability of vesicles (Wu and Saggau, 1994; Stevens and Wang, 1995). On the minutes time scale, however, it is extremely unlikely that $\mathrm{Ca}^{2+}$ remains elevated during the enhanced release (see Zucker, 1993; Augustine et al., 1994; Delaney and Tank, 1994; Regehr et al., 1994; Liu and Tsien, 1995; Tank et al., 1995; Neveu and Zucker, 1996). The data show that the enhanced release continued for minutes after the nicotine had been washed away.

The forms of enhancement lasting minutes might require that the incoming calcium acts as a second messenger to modify indirectly exocytotic processes leading to minutes-scale enhancement of synaptic transmission (Zucker, 1993; Augustine et al., 1994; Neveu and Zucker, 1996). Previous studies of glutamatergic synaptic plasticity, such as short-term and long-term potentiation
A

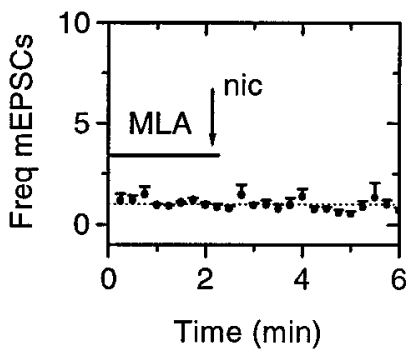

C

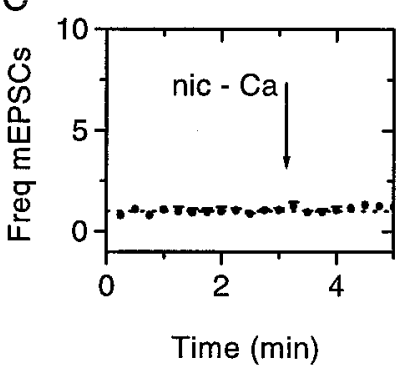

$\mathrm{D}$

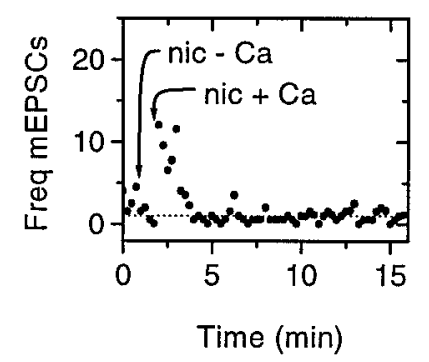

Figure 5. The minutes-scale increase in mEPSC frequency shows the pharmacology of $\alpha 7$-containing nAChRs and requires external calcium. $A$, In the presence of $5 \mathrm{nM}$ MLA (solid bar), five nicotine applications (arrow) did not increase the mEPSC frequency $(n=7)$. B. Five applications of nicotine (arrow) in the presence of 5 nM MLA (solid bar) did not enhance the mEPSC frequency, but five nicotine applications (arrow) after the washout of MLA did increase the frequency. $C$, In $\mathrm{Ca}^{2+}$-free solutions $\left(0\right.$ or $\left.50 \mu \mathrm{M} \mathrm{Ca}^{2+}\right)$, nicotine applications (arrow, nic $-\mathrm{Ca}$ ) did not increase mEPSC frequency $(n=9)$. $D$, Five applications of nicotine in $\mathrm{Ca}^{2+}$-free solution (arrow, nic $-\mathrm{Ca}$ ) did not increase mEPSC frequency; however, in a solution containing $2.5 \mathrm{mM} \mathrm{Ca}^{2+}$, five nicotine applications (arrow, nic $+\mathrm{Ca}$ ) did increase the frequency. The time taken for the nicotine applications is not shown.

and depression, suggest mechanisms for synaptic changes that might be initiated by nAChR activity (Kauer et al., 1988; Malgaroli and Tsien, 1992; Malenka and Nicoll, 1993; Stevens et al., 1994; Tong et al., 1996). It seems reasonable to anticipate that a properly localized $\mathrm{Ca}^{2+}$ influx mediated by $\mathrm{nAChRs}$ could initiate enzymatic activity that is known to modify glutamatergic synapses under other circumstances. However, final verification of those mechanisms must await further experimentation.

Nicotine also increased the amplitude of evoked EPSCs. This result indicates that the activation of $\mathrm{nAChRs}$ can modulate the responsiveness of the presynaptic terminal to a subsequent action potential. The influx of $\mathrm{Ca}^{2+}$ through presynaptic voltage-gated channels in response to an action potential normally increases the probability of releasing neurotransmitter. However, the presynaptic action potential does not guarantee release (Huang and Stevens, 1997). Therefore, the activation of presynaptic nAChRs just before or during the arrival of an action potential can increase the probability of successful synaptic transmission because the $\mathrm{Ca}^{2+}$ entry via the two pathways integrates in the presynaptic terminal. Consequently, properly timed nicotinic activity can increase the fidelity of particular synaptic events.

Not only can nicotinic activity change the amplitude of evoked EPSCs, but it also can alter the relationship between closely timed synaptic events. Our results with eEPSCs show that nicotinic cholinergic activity can reverse the strength of paired eEPSCs. Without nicotinic activity the first eEPSC of a closely spaced 


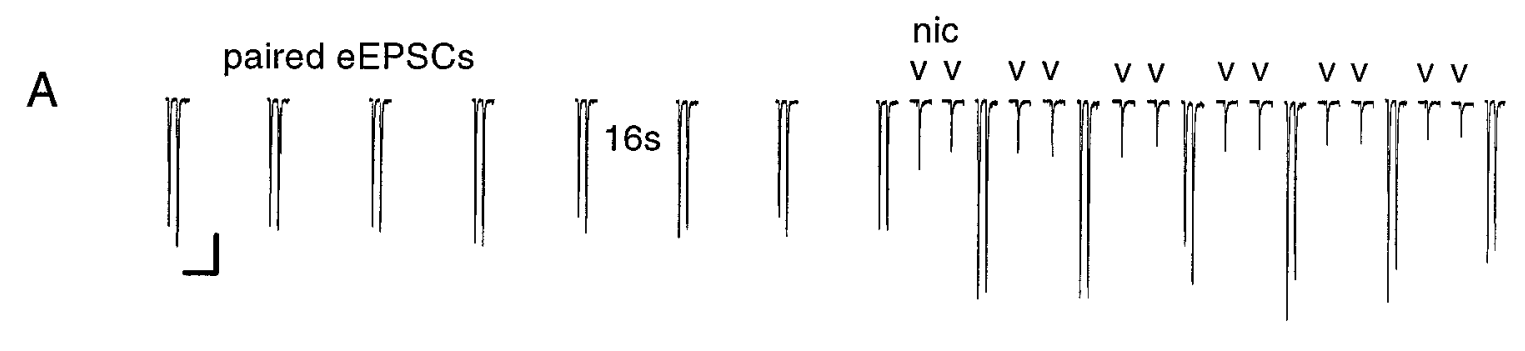

\section{B}

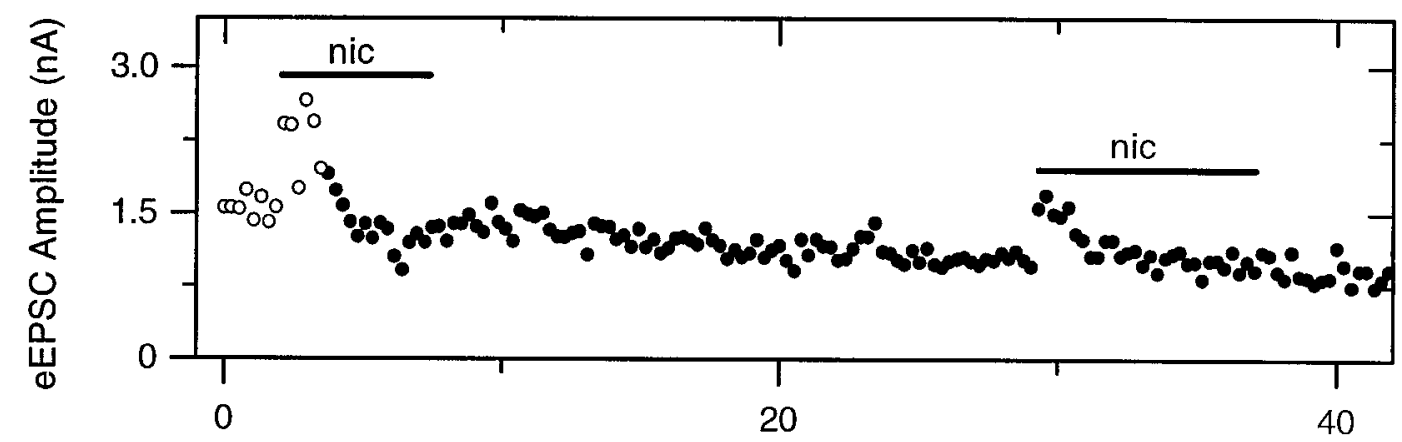

Time (min)
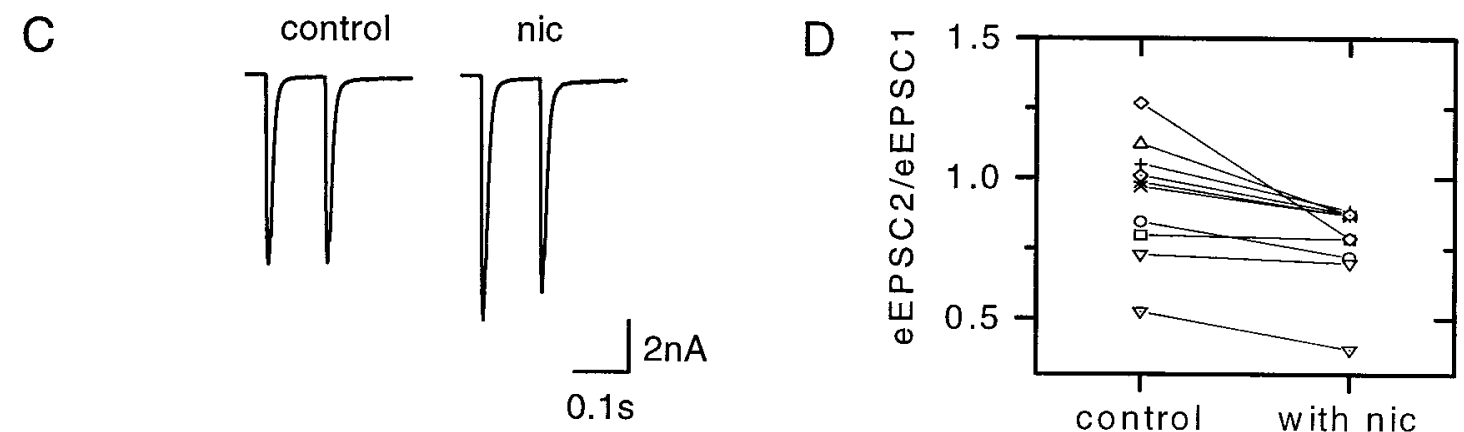

Figure 6. Nicotinic stimulation enhanced the amplitude of evoked EPSCs and altered the relationship between pairs of eEPSCs. $A$, The experimental paradigm was as follows: pairs of eEPSCs (100 msec apart) were measured every $16 \mathrm{sec}$ before and during interleaved applications of $0.5 \mathrm{~mm}$ nicotine (arrowheads, nic). The nicotine applications were $8 \mathrm{sec}$ apart. The $\mathrm{nAChR}$ currents decreased in size as the experiment progressed (in large part) because there was accumulative desensitization. Calibration: $0.5 \mathrm{nA}, 0.4 \mathrm{sec} . B$, The amplitude of the first eEPSC is plotted versus time, and the solid bars indicate when nicotine applications were interleaved between the eEPSCs. The first 14 eEPSCs, which are shown in $A$, are plotted as open circles. The gradual decrease in the amplitude of the eEPSCs over the course of the experiment was common, but not always present. The second set of nicotine applications (second solid bar) induces a smaller increase in the amplitude of the eEPSCs. $C$, An example indicates the typical change in the relationship between the pairs of eEPSCs compared before nicotine (control) and during interleaved nicotine applications (nic). D, The average ratio of eEPSC2/eEPSC1 is plotted before (control) and at the maximum of the enhancement (with nic) for each experiment $(n=10)$. In every case the ratio decreased.

pair is smaller, giving paired-pulse facilitation to the second eEPSC. During nicotinic activity, however, that relationship reverses so that the first eEPSC of the pair can become substantially larger than the second, giving paired-pulse depression. Thus, cholinergic stimulation mediated by nAChRs can alter the relationship between the incoming presynaptic activity and outgoing postsynaptic signaling along glutamatergic fibers. The same information arriving along the same glutamatergic afferents will be processed differently when properly timed nicotinic activity converges onto the glutamatergic terminals. Early in the progression of Alzheimer's disease, cholinergic inputs degenerate and the number of hippocampal nAChRs decreases (Rinne et al., 1991; Nordberg, 1994; Perry et al., 1995). The cognitive deficits associated with Alzheimer's disease could arise, in part, from loss of the cholinergic synaptic mechanisms that modulate the gain and fidelity of hippocampal synaptic transmission. Related mechanisms are also likely to be important elsewhere in the brain.

\section{REFERENCES}

Aiba A, Chen C, Herrup K, Rosenmund C, Stevens CF, Tonegawa S (1994) Reduced hippocampal long-term potentiation and contextspecific deficit in associative learning in mGluR1 mutant mice. Cell 79:365-375.

Aigner TG (1995) Pharmacology of memory: cholinergic-glutamatergic interactions. Curr Opin Neurobiol 5:155-160.

Albuquerque EX, Alkondon M, Pereira EF, Castro NG, Schrattenholz A, Barbosa CT, Bonfante-Cabarcas R, Aracava Y, Eisenberg HM, Maelicke A (1997) Properties of neuronal nicotinic acetylcholine receptors: pharmacological characterization and modulation of synaptic function. J Pharmacol Exp Ther 280:1117-1136.

Alkondon M, Albuquerque EX (1991) Initial characterization of the nicotinic acetylcholine receptors in rat hippocampal neurons. J Recept Res 11:1001-1021.

Alkondon M, Albuquerque EX (1993) Diversity of nicotinic acetylcholine receptors in rat hippocampal neurons. I. Pharmacological and functional evidence for distinct structural subtypes. J Pharmacol Exp Ther 265:1455-1473.

Alkondon M, Pereira EF, Wonnacott S, Albuquerque EX (1992) Block- 
ade of nicotinic currents in hippocampal neurons defines methyllycaconitine as a potent and specific receptor antagonist. Mol Pharmacol 41:802-808.

Alkondon M, Rocha ES, Maelicke A, Albuquerque EX (1996) Diversity of nicotinic acetylcholine receptors in rat brain. V. $\alpha$-Bungarotoxinsensitive nicotinic receptors in olfactory bulb neurons and presynaptic modulation of glutamate release. $J$ Pharmacol Exp Ther 278:1460-1471.

Alkondon M, Pereira EF, Barbosa CT, Albuquerque EX (1997) Neuronal nicotinic acetylcholine receptor activation modulates gammaaminobutyric acid release from CA1 neurons of rat hippocampal slices. J Pharmacol Exp Ther 283:1396-1411.

Alonso JR, Amaral DG (1995) Cholinergic innervation of the primate hippocampal formation. I. Distribution of choline acetyltransferase immunoreactivity in the Macaca fascicularis and Macaca mulatta monkeys. J Comp Neurol 355:135-170.

Amador M, Dani JA (1995) Rapid mechanism for modulating nicotinic cholinergic synaptic transmission. J Neurosci 15:4525-4532.

Amar M, Thomas P, Johnson C, Lunt GG, Wonnacott S (1993) Agonist pharmacology of the neuronal $\alpha 7$ nicotinic receptor expressed in $X e$ nopus oocytes. FEBS Lett 327:284-288.

Anand R, Peng X, Ballesta JJ, Lindstrom J (1993) Pharmacological characterization of $\alpha$-bungarotoxin-sensitive acetylcholine receptors immunoisolated from chick retina: contrasting properties of $\alpha 7$ and $\alpha 8$ subunit-containing subtypes. Mol Pharmacol 44:1046-1050.

Augustine GJ, Betz H, Bommert K, Charlton MP, DeBello WM, Hans M, Swandulla D (1994) Molecular pathways for presynaptic calcium signaling. Adv Second Messenger Phosphoprotein Res 29:139-154.

Bekkers JM, Stevens CF (1991) Excitatory and inhibitory autaptic currents in isolated hippocampal neurons maintained in cell culture. Proc Natl Acad Sci USA 88:7834-7838..

Bertrand D, Galzi JL, Devillers-Thiery A, Bertrand S, Changeux J-P (1993) Mutations at two distinct sites within the channel domain M2 alter calcium permeability of neuronal $\alpha 7$ nicotinic receptor. Proc Natl Acad Sci USA 90:6971-6975.

Bonfante-Cabarcas R, Swanson KL, Alkondon M, Albuquerque EX (1996) Diversity of nicotinic acetylcholine receptors in rat hippocampal neurons. IV. Regulation by external $\mathrm{Ca}^{2+}$ of $\alpha$-bungarotoxinsensitive receptor function and of rectification induced by internal $\mathrm{Mg}^{2+}$. J Pharmacol Exp Ther 277:432-444.

Castro NG, Albuquerque EX (1995) $\alpha$-Bungarotoxin-sensitive hippocampal nicotinic receptor channel has a high calcium permeability. Biophys J 68:516-524.

Cimino M, Marini P, Fornasari D, Cattabeni F, Clementi F (1992) Distribution of nicotinic receptors in cynomolgus monkey brain and ganglia: localization of $\alpha 3$ subunit mRNA, $\alpha$-bungarotoxin, and nicotine binding sites. Neuroscience 51:77-86.

Conroy WG, Vernallis AB, Berg DK (1992) The $\alpha 5$ gene product assembles with multiple acetylcholine receptor subunits to form distinctive receptor subtypes in brain. Neuron 9:679-691.

Cooper E, Couturier S, Ballivet M (1991) Pentameric structure and subunit stoichiometry of a neuronal acetylcholine receptor. Nature 350:235-238.

Couturier S, Bertrand D, Matter JM, Hernandez MC, Bertrand S, Millar N, Valera S, Barkas T, Ballivet M (1990) A neuronal nicotinic acetylcholine receptor subunit $(\alpha 7)$ is developmentally regulated and forms a homo-oligomeric channel blocked by $\alpha$-BTX. Neuron 5:847-856.

Delaney KR, Tank DW (1994) A quantitative measurement of the dependence of short-term synaptic enhancement on presynaptic residual calcium. J Neurosci 14:5885-5902.

Deneris ES, Connolly J, Boulter J (1988) Primary structure and expression of $\beta 2$ : a novel subunit of neuronal nicotinic acetylcholine receptors. Neuron 1:45-54.

Dineley-Miller K, Patrick J (1992) Gene transcripts for the nicotinic acetylcholine receptor subunit, $\beta 4$, are distributed in multiple areas of the rat central nervous system. Mol Brain Res 16:339-344.

Flood P, Ramirez-Latorre J, Role L (1997) $\alpha 4 \beta 2$ neuronal nicotinic acetylcholine receptors in the central nervous system are inhibited by isoflurane and propofol, but $\alpha 7$-type nicotinic acetylcholine receptors are unaffected. Anesthesiology 86:859-865.

Goda Y, Stevens CF (1996) Synaptic plasticity: the basis of particular types of learning. Curr Biol 6:375-378.

Gray R, Rajan AS, Radcliffe KA, Yakehiro M, Dani JA (1996) Hippocampal synaptic transmission enhanced by low concentrations of nicotine. Nature 383:713-716.
Guo J-Z, Tredway TL, Vincent A, Chiappinelli VA (1998) Glutamate and GABA release are enhanced by different subtypes of presynaptic nicotinic receptors in the lateral geniculate nucleus. J Neurosci 18:1963-1969.

Huang EP, Stevens CF (1997) Estimating the distribution of synaptic reliabilities. J Neurophysiol 78:2870-2880.

Kasa P (1986) The cholinergic systems in brain and spinal cord. Prog Neurobiol 26:211-272.

Kauer JA, Malenka RC, Nicoll RA (1988) NMDA application potentiates synaptic transmission in the hippocampus. Nature 334:250-252.

Lena C, Changeux J-P (1997) Role of $\mathrm{Ca}^{2+}$ ions in nicotinic facilitation of GABA release in mouse thalamus. J Neurosci 17:576-585.

Lena C, Changeux J-P, Mulle C (1993) Evidence for "preterminal" nicotinic receptors on GABAergic axons in the rat interpeduncular nucleus. J Neurosci 13:2680-2688.

Lester RAJ, Dani JA (1994) Time-dependent changes in central nicotinic acetylcholine channel kinetics in excised patches. Neuropharmacology 33:27-34.

Levin ED (1992) Nicotinic systems and cognitive function. Psychopharmacology 108:417-431.

Li X, Rainnie DG, McCarley RW, Greene RW (1998) Presynaptic nicotinic receptors facilitate monoaminergic transmission. J Neurosci 18:1904-1912.

Liu G, Tsien RW (1995) Properties of synaptic transmission at single hippocampal synaptic boutons. Nature 375:404-408.

Madison DV, Malenka RC, Nicoll RA (1991) Mechanisms underlying long-term potentiation of synaptic transmission. Annu Rev Neurosci 14:379-397.

Malenka RC, Nicoll RA (1993) NMDA-receptor-dependent synaptic plasticity: multiple forms and mechanisms. Trends Neurosci 16:521-527.

Malgaroli A, Tsien RW (1992) Glutamate-induced long-term potentiation of the frequency of miniature synaptic currents in cultured hippocampal neurons. Nature 357:134-139.

Maurice T, Hiramatsu M, Kameyama T, Hasegawa T, Nabeshima T (1994) Behavioral evidence for a modulating role of sigma ligands in memory processes. I. Attenuation of dizocilpine (MK-801)-induced amnesia. Brain Res 647:44-56.

McGehee DS, Role LW (1995) Physiological diversity of nicotinic acetylcholine receptors expressed by vertebrate neurons. Annu Rev Physiol 57:521-546.

McGehee DS, Heath MJ, Gelber S, Devay P, Role LW (1995) Nicotine enhancement of fast excitatory synaptic transmission in CNS by presynaptic receptors. Science 269:1692-1696.

McHugh TJ, Blum KI, Tsien JZ, Tonegawa S, Wilson MA (1996) Impaired hippocampal representation of space in CA1-specific NMDAR1 knockout mice. Cell 87:1339-1349.

McMahon LL, Yoon KW, Chiappinelli VA (1994) Nicotinic receptor activation facilitates GABAergic neurotransmission in the avian lateral spiriform nucleus. Neuroscience 59:689-698.

Mennerick S, Zorumski CF (1995) Paired-pulse modulation of fast excitatory synaptic currents in microcultures of rat hippocampal neurons. J Physiol (Lond) 488:85-101.

Mennerick S, Zorumski CF (1996) Postsynaptic modulation of NMDA synaptic currents in rat hippocampal microcultures by paired-pulse stimulation. J Physiol (Lond) 490[Pt 2]:405-407.

Moss BL, Role LW (1993) Enhanced ACh sensitivity is accompanied by changes in $\mathrm{ACh}$ receptor channel properties and segregation of $\mathrm{ACh}$ receptor subtypes on sympathetic neurons during innervation in vivo. J Neurosci 13:13-28.

Mulle C, Léna C, Changeux JP (1992) Potentiation of nicotinic receptor response by external calcium in rat central neurons. Neuron 8:937-945.

Neveu D, Zucker RS (1996) Postsynaptic levels of $\left[\mathrm{Ca}^{2+}\right]_{\mathrm{i}}$ needed to trigger LTD and LTP. Neuron 16:619-629.

Nordberg A (1994) Human nicotinic receptors-their role in aging and dementia. Neurochem Int 25:93-97.

Ohno M, Yamamoto T, Watanabe S (1993) Blockade of hippocampal nicotinic receptors impairs working memory but not reference memory in rats. Pharmacol Biochem Behav 45:89-93.

Perry EK, Morris CM, Court JA, Cheng A, Fairbairn AF, McKeith IG, Irving D, Brown A, Perry RH (1995) Alteration in nicotine binding sites in Parkinson's disease, Lewy body dementia, and Alzheimer's disease: possible index of early neuropathology. Neuroscience 64:385-395.

Pugh PC, Berg DK (1994) Neuronal acetylcholine receptors that bind 
$\alpha$-bungarotoxin mediate neurite retraction in a calcium-dependent manner. J Neurosci 14:889-896.

Radcliffe KA, Fisher J, Gray R, Dani JA (1998) Nicotine potentiates glutamate and GABA synaptic transmission. Ann NY Acad Sci, in press.

Rae J, Cooper K, Gates P, Watsky M (1991) Low access resistance perforated patch recordings using amphotericin B. J Neurosci Methods $37: 15-26$.

Ramirez-Latorre J, Yu C, Qu X, Perin F, Karlin A, Role L (1996) Functional contributions of $\alpha 5$ subunit to neuronal acetylcholine receptor channels. Nature 380:347-351.

Rathouz MM, Berg DK (1994) Synaptic-type acetylcholine receptors raise intracellular calcium levels in neurons by two mechanisms. J Neurosci 14:6935-6945.

Rathouz MM, Vijayaraghavan S, Berg DK (1995) Acetylcholine differentially affects intracellular calcium via nicotinic and muscarinic receptors on the same population of neurons. J Biol Chem 270:14366-14375.

Regehr WG, Delaney KR, Tank DW (1994) The role of presynaptic calcium in short-term enhancement at the hippocampal mossy fiber synapse. J Neurosci 14:523-537.

Rinne JO, Myllkyla T, Lonnberg P, Marjamaki P (1991) A postmortem study of brain nicotinic receptors in Parkinson's and Alzheimer's disease. Brain Res 547:167-170.

Role LW, Berg DK (1996) Nicotinic receptors in the development and modulation of CNS synapses. Neuron 16:1077-1085.

Sargent PB (1993) The diversity of neuronal nicotinic acetylcholine receptors. Annu Rev Neurosci 16:403-443.

Schoepfer R, Conroy W, Whiting P, Gore M, Lindstrom J (1990) Brain $\alpha$-bungarotoxin binding protein cDNAs and mAbs reveal subtypes of this branch of the ligand-gated ion channel gene superfamily. Neuron 5:35-48.

Séguéla P, Wadiche J, Dineley-Miller K, Dani JA, Patrick JW (1993) Molecular cloning, functional properties, and distribution of rat brain $\alpha 7$ : a nicotinic cation channel highly permeable to calcium. J Neurosci 13:596-604.

Stevens CF, Wang Y (1995) Facilitation and depression at single central synapses. Neuron 14:795-802.

Stevens CF, Tonegawa S, Wang Y (1994) The role of calciumcalmodulin kinase II in three forms of synaptic plasticity. Curr Biol 4:687-693.

Tank W, Regehr WG, Delaney KR (1995) A quantitative analysis of presynaptic calcium dynamics that contribute to short-term enhancement. J Neurosci 15:7940-7952.

Tong G, Malenka RC, Nicoll RA (1996) Long-term potentiation in cultures of single hippocampal granule cells: a presynaptic form of plasticity. Neuron 16:1147-1157.

Ullian EM, McIntosh JM, Sargent PB (1997) Rapid synaptic transmis- sion in the avian ciliary ganglion is mediated by two distinct classes of nicotinic receptors. J Neurosci 17:7210-7219.

Unwin N (1995) Acetylcholine receptor channel imaged in the open state. Nature 373:37-43.

Vernino S, Amador M, Luetje CW, Patrick J, Dani JA (1992) Calcium modulation and high calcium permeability of neuronal nicotinic acetylcholine receptors. Neuron 8:127-134.

Vidal C, Changeux J-P (1993) Nicotinic and muscarinic modulations of excitatory synaptic transmission in the rat prefrontal cortex in vitro. Neuroscience 56:23-32.

Vijayaraghavan S, Pugh PC, Zhang ZW, Rathouz MM, Berg DK (1992) Nicotinic receptors that bind $\alpha$-bungarotoxin on neurons raise intracellular free $\mathrm{Ca}^{2+}$. Neuron 8:353-362.

Wada E, Wada K, Boulter J, Deneris E, Heinemann S, Patrick J, Swanson LW (1989) Distribution of $\alpha 2, \alpha 3, \alpha 4$, and $\beta 2$ neuronal nicotinic receptor subunit mRNAs in the central nervous system: a hybridization histochemical study in the rat. J Comp Neurol 284:314-355.

Wang JH, Kelly PT (1997) Attenuation of paired-pulse facilitation associated with synaptic potentiation mediated by postsynaptic mechanisms. J Neurophysiol 78:2707-2716.

Wilson Horch HL, Sargent PB (1996) Synaptic and extrasynaptic distribution of two distinct populations of nicotinic acetylcholine receptor clusters in the frog cardiac ganglion. J Neurocytol 25:67-77.

Wonnacott S (1997) Presynaptic nicotinic ACh receptors. Trends Neurosci 20:92-98.

Woolf NJ (1991) Cholinergic systems in mammalian brain and spinal cord. Prog Neurobiol 37:475-524.

Wu LG, Saggau P (1994) Presynaptic calcium is increased during normal synaptic transmission and paired-pulse facilitation, but not in long-term potentiation in area CA1 of hippocampus. J Neurosci 14:645-654.

Yoshida K, Oka H (1995) Topographical projections from the medial septum-diagonal band complex to the hippocampus: a retrograde tracing study with multiple fluorescent dyes in rats. Neurosci Res 21:199-209.

Zarei M, Dani JA (1994) Ionic permeability characteristics of the $N$-methyl-D-aspartate receptor channel. J Gen Physiol 103:231-248.

Zarei M, Dani JA (1995) Structural basis for explaining open-channel blockade of the NMDA receptor. J Neurosci 15:1446-1454.

Zhang ZW, Vijayaraghavan S, Berg DK (1994) Neuronal acetylcholine receptors that bind $\alpha$-bungarotoxin with high affinity function as ligandgated ion channels. Neuron 12:167-177.

Zorumski CF, Thio LL, Isenberg KE, Clifford DB (1992) Nicotinic acetylcholine currents in cultured postnatal rat hippocampal neurons. Mol Pharmacol 41:931-936.

Zucker RS (1993) Calcium and transmitter release. J Physiol (Paris) $87: 25-36$. 